their study. Hoping I have not trespassed too much upon your own or your readers' patience, I beg leave to subscribe myself yours most respectfully,

Greenwich, Nov, 26, 1840.

Wm. Sturton.

\section{EMENAGOGUES IN VICARIOUS DISCHARGES.}

\section{To the Editor of The LANCET.}

SIR:-Should you consider the annexed case worthy of publication, I think it may prove of some interest, as tending to show the use of very moderate doses of emenagogue medicines, in cases of vicarious discharge.

The empirical practice of exhibiting large quantities of uterine stimulants cannot be too strongly deprecated, and it is a custom which is prevalent to an alarming degree. I have the honour to be, Sir, your very obedient servant,

Edward Boulger, Surgeon.

27, London-street, Reading, Nov. 24, 1840.

M. C., a domestic, ætat 29 years, single, applied to me on account of a discharge which issued at monthly periods from beneath the left mamma. Eight years ago she fell from a chair whilst employed in cleaning windows. She was menstruating, for the first time, when the accident happened. A bruise, with abrasion beneath the left breast, was occasioned by the fall. Up to the time when she consulted me she had never again menstruated (eight years having elapsed since the first appearance of the catamenia), but a red, glairy fluid had continued to flow at monthly periods from the abrasion which had never quite healed, although between whiles it always got considerably better.

Upon examination, the following appearances were present. Immediately beneath the left breast was a small patch, about the size of a crown-piece, with irregular edges; marked and intersected with raghades, as in psoriasis: upon this patch were two small excoriations, from which the discharge might be seen to issue. She complained of the itching of the sore, and the annoyance of the discharge; head-ache; giddiness ; costive bowels and tympanitis. Had consulted two medical men, who both recommended her to have the part excised; the result shows how unnecessary such a step would have been.

I ordered her to apply to the excoriated part a lotion, consisting of a drachm of sulphate of zinc to a pint and a half of water, frequently during the day; and a poultice, made with the same lotion, at night. To take a pill every night, composed of one grain of sulphate of iron, and five grains of the aloes and myrrh pill, and two table-spoonsful of the following mixture every morning :-

$\mathrm{R}$ Compound steel mixture ; Compound decoction of aloes; of each, ziss.

After persevering in this plan for three weeks the bowels were acting regularly, the catamenia had appeared, and the side was perfectly healed. The medicines were discontinued, and no return of the disease has been perceived, although twelve months have elapsed. Occasional aperients have been administered.

\section{N I T RATE OF S I VER,} AS AN INTERNAL REMEDY.

\section{To the Editor of THE LANCET.}

Sir:-In your Journal of December 12th, is a communication suggesting the internal exhibition of the nitrate of silver, in reference to which I subscribe the following remarks, for the consideration of those who, appreciating the potency of the means, might feel disposed to hazard so unlikely a chance of administering it with a happy result.

The catalogue of remedies furnished by chemical science as auxiliaries to the practice of medicine, presents no preparation of greater import or efficacy than the nitrate of silver; and it is much to be lamented, that so insuperable an objection to its internal application should exist, as the permanent and unearthly disfigurement consequent upon its administration. Until this unconquered deformity can be controlled, until the reasonable certainty of its prevention can be established upon a scientific basis, no medical practitioner is justified in experimentalising upon the afficted, confiding, and short-sighted patient; who, if relieved, or even cured, of the previously inveterate and fiend-like paroxysms of epilepsy, the most excruciating neuralgic affection, or the most loathsome cutaneous eruption would, in all probability, then take alarm, and feel horror-stricken at his unsightly expression, and reflect eternal discredit upon the adviser of a stain so obnoxious, as well from its rarity as permanency.

Your correspondent builds his suggestion upon the fact, that hydriodate of potash removes the external stains produced by nitrate of silver, and adds, that possibly a like consequence might result from its internal use. In the first place, however probable the supposition, it is by no means satisfactorily proved, that the discolourations upon and beneath the surface, are chemically analogous. Nitrate of silver applied externally, speedily suffers decomposition through the agency of light, demonstrating an evolution of nitrous gas, and a deposition of oxide of sil- 